\title{
Hypopituitarism and brain injury: recent advances in screening and management
}

\author{
Johanna Pickel $^{1 *}$, Harald J Schneider ${ }^{2}$ and Günter K Stalla ${ }^{1}$
}

\author{
Addresses: ${ }^{1}$ Clinical Neuroendocrinology Group, Max Planck Institute of Psychiatry, Kraepelinstr 10, 80804 Munich, Germany; \\ ${ }^{2}$ Medizinische Klinik - Innenstadt, Ludwig-Maximilian-University, Ziemssenstr 1, 80336 Munich, Germany \\ *Corresponding author: Johanna Pickel (pickel@mpipsykl.mpg.de) \\ Fl000 Medicine Reports 2009, I:63 (doi:10.3410/MI-63)
}

The electronic version of this article is the complete one and can be found at: http://F/000.com/Reports/Medicine/content/I/63

\begin{abstract}
This review gives an overview of the research on hypothalamopituitary dysfunction as a potential consequence of traumatic brain injury, including the natural history of this complication and its clinical and public health implications.
\end{abstract}

\section{Introduction and context}

With an overall incidence of 235 per 100,000 persons per year, traumatic brain injury (TBI) is a major public health problem [1]. In young adults, TBI is the leading cause of death and disability [2]. Aneurysmal subarachnoid hemorrhage (SAH) occurs in 6-10 per 100,000 persons each year [3]. Both TBI and SAH leave many survivors with significant adverse physical and psychological sequelae of the trauma $[4,5]$. In recent years, neuroendocrine dysfunction following TBI and aneurysmal SAH was reported with a much higher prevalence than previously suspected. Untreated hypopituitarism is associated with serious morbidity [6-9] and premature mortality $[10,11]$. Serious and life-threatening adrenal crises secondary to acute adrenocorticotropic hormone deficiency in TBI patients have been highlighted in the literature recently with significant improvement following glucocorticoid replacement [12]. In addition, hypopituitarism can aggravate the underlying physical and neuropsychiatric deficits often following TBI, leading to impaired recovery and quality of life (Qol). Here, we review recent investigations that provide relevant information on the screening and management of these patients.

\section{Recent advances}

Prevalence

Aimaretti and colleagues [13] had reported a high prevalence of hypopituitarism in patients after TBI and SAH in a prospective multicentre study in over 100 patients. It was demonstrated that partial dysfunction may improve with time but that panhypopituitarism, which occurred in 5\% of patients, is irreversible. Up to one-third of patients were left with pituitary insufficiency; growth hormone deficiency was the most common deficit, followed by hypogonadism. The severity of brain injury did not influence the degree of hypopituitarism. Faculty of 1000 member Ho, in an evaluation [14] of that paper, states that clinicians should always evaluate pituitary function following brain injury. The largest systematic review on hypothalamopituitary dysfunction following TBI and aneurysmal SAH, published by Schneider and colleagues [15], summarizes 19 studies comprising 1,137 patients. The pooled prevalences of hypopituitarism in the chronic phase after TBI and SAH were $27.5 \%$ and $47 \%$, respectively. However, a large variation in prevalence of hormone deficiencies was found in the different studies. Possible reasons for this were patient selection, study designs, and tests used. In an evaluation [16] of that paper, Faculty of 1000 member Marion states that, due to the surprisingly high prevalence of hypopituitarism in that meta-analysis, the routine for patients with TBI or SAH should include pituitary screening prior to release from the acute care hospital as well as periodical controlling later on. 


\section{Risk factors for hypopituitarism after traumatic brain injury}

In the same systematic review, after pooling of all relevant studies, severity of brain injury was found to be associated with occurrence of hypopituitarism. Several prospective studies with a follow-up of 1-3 years confirm the results of previous retrospective analyses. Predictive factors are analysed and correlated with outcome. In these recent studies, an association between severity of trauma and acute and long-term neuroendocrine consequences could be demonstrated [17-21]. Further potential risk factors identified were diffuse axonal injury, basal skull fracture, and older age in one study [22], and increased intracranial pressure and prolonged intensive care unit stay in another study [19].

\section{Natural course of post-traumatic hypopituitarism}

Early neuroendocrine abnormalities were transient in some patients, whereas less commonly, hypopituitarism evolved over time in others. In one study, there was little further change of endocrine function after 6 months after trauma [23]. Two other studies showed independently that, between 3 and 12 months after trauma, pituitary function may either recover or worsen, the latter being less common $[13,24]$.

\section{Clinical relevance}

A study published in 2008 by Bavisetty and colleagues [20] on chronic hypopituitarism after TBI focused on risk assessment and relationship to outcome. Six to nine months after TBI, $21 \%$ of their patients required hormone replacement of at least one axis. Most common and associated with more disability, depression, and reduced Qol was growth hormone deficiency/growth hormone insensitivity (occurring in 16\%). Klose and colleagues [25] demonstrated that post-traumatic hypopituitarism is associated with an unfavourable body composition and lipid profile and a decreased Qol 12 months after injury. In 2007, Bondanelli and colleagues [26] found that anterior pituitary function may predict functional and cognitive outcome in TBI patients undergoing rehabilitation.

\section{Implications for clinical practice}

A significant percentage of trauma patients are currently living with undiagnosed endocrinopathies. Routine early screening for pituitary dysfunction in patients with TBI and SAH is likely to improve the Qol for these patients by detecting unexpected pituitary dysfunction and leading to the provision of replacement hormone therapy for a substantial number. Given the large number of individuals who fall victim to TBI and SAH each year, post-traumatic hypopituitarism becomes an entity of major public health significance. Based on the incidence of patients hospitalized for TBI and SAH reported in the literature and the frequencies of hypopituitarism in these patients, the incidence of hypopituitarism caused by these disorders is estimated to be more than 30 per 100,000 per year [6]. This by far outnumbers all other well-recognized causes of hypopituitarism [27]. Due to a potential selection bias, this is (at present) only a rough estimate and should be considered with caution. However, it is clear that a large number of patients with hypopituitarism after TBI or $\mathrm{SAH}$ remain undiagnosed and untreated. Yet further studies are needed. Particularly, prospective clinical trials to assess the effects and risks of hormone replacement in these patients are still lacking.

\section{Recommendations for screening}

Since the sequelae of brain injury may mask the signs of hypopituitarism, the threshold for endocrine assessment should be low, and in cases of uncertainty, endocrine assessment should be performed at least once. Also, in patients with basal skull fractures, diffuse axonal injury, increased intracranial pressure or prolonged intensive care unit stay, pituitary assessment should be considered. In the acute phase, cortisol deficiency should not be missed. Screening for low basal cortisol should be performed in patients with clinical signs suggestive of hypopituitarism or the abovementioned risk factors. Screening for further deficiencies, including stimulation tests, should be performed in patients at risk after 3-6 months after trauma [15]. Close collaboration between the neurosurgery, endocrinology, rehabilitation medicine and other disciplines is essential in order to ensure optimal delivery of care. If hypopituitarism is detected, hormone replacement therapy should be given as appropriate and has the potential to improve recovery, rehabilitation and Qol for those patients. Systematic therapy studies showing the benefits of optimal hormone substitution are needed.

\section{Abbreviations}

Qol, quality of life; SAH, subarachnoid hemorrhage; TBI, traumatic brain injury.

\section{Competing interests}

JP received travel grants from Novo Nordisk. HJS received research grants from Pfizer Inc, speaker fees and travel grants from Pfizer Inc and Novo Nordisk and travel grants from Eli Lilly and Company. GKS received speaker and/or consultant fees from Pfizer Inc, Novartis, Novo Nordisk and Ipsen, travel grants from Pfizer Inc and research grants from Eli Lilly and Company, Pfizer Inc, Novartis, Novo Nordisk and Ipsen. 


\section{References}

I. Tagliaferri F, Compagnone C, Korsic M, Servadei F, Kraus J: A systematic review of brain injury epidemiology in Europe. Acta Neurochir (Wien) 2006, I48:255-68.

2. van Baalen B, Odding E, Maas Al, Ribbers GM, Bergen MP, Stam HJ: Traumatic brain injury: classification of initial severity and determination of functional outcome. Disabil Rehabil 2003, 25:9-18.

3. van Gijn J, Kerr R, Rinkel G: Subarachnoid haemorrhage. Lancet 2007, 369:306-18.

4. Hütter BO, Kreitschmann-Andermahr I, Mayfrank L, Rohde V, Spetzger U, Gilsbach JM: Functional outcome after aneurysmal subarachnoid hemorrhage. Acta Neurochir Suppl (Wien) 1999, 72: $157-74$.

5. Salmond $\mathrm{CH}$, Sahakian $\mathrm{BJ}$ : Cognitive outcome in traumatic brain injury survivors. Curr Opin Crit Care 2005, I I: I I I-6.

6. Schneider HJ, Aimaretti G, Kreitschmann-Andermahr I, Stalla G, Ghigo E: Hypopituitarism. Lancet 2007, 369:|46|-70.

7. Vance ML: Hypopituitarism. N Engl J Med 1994, 330: I65 I-62.

8. Erfurth EM, Hagmar L: Cerebrovascular disease in patients with pituitary tumors. Trends Endocrinol Metab 2005, 16:334-42.

9. Gola M, Bonadonna S, Doga M, Giustina A: Clinical review: growth hormone and cardiovascular risk factors. J Clin Endocrinol Metab 2005, 90: 1864-70.

10. Rosen T, Bengtsson BA: Premature mortality due to cardiovascular disease in hypopituitarism. Lancet 1990, 336:285-8.

II. Tomlinson JW, Holden N, Hills RK, Wheatley K, Clayton RN, Bates AS, Sheppard MC, Stewart PM: Association between premature mortality and hypopituitarism. West Midlands Prospective Hypopituitary Study Group. Lancet 2001, 357:425-3I.

12. Agha A, Ryan J, Sherlock M, Thompson C]: Spontaneous recovery from posttraumatic hypopituitarism. Am J Phys Med Rehabil 2005, 84:381-5.

13. Aimaretti G, Ambrosio MR, Di Somma C, Gasperi M, Cannavò S, Scaroni C, Fusco A, Del Monte P, De Menis E, Faustini-Fustini M, Grimaldi F, Logoluso F, Razzore P, Rovere S, Benvenga S, Degli Uberti EC, De Marinis L, Lombardi G, Mantero F, Martino E, Giordano G, Ghigo E: Residual pituitary function after brain injury-induced hypopituitarism: a prospective I2-month study. J Clin Endocrinol Metab 2005, 90:6085-92.

\section{Changes Clinical Practice}

FI000 Factor 3.0 Recommended

Evaluated by Ken Ho 07 Feb 2006

14. Ho K: Evaluation of: Aimaretti G, Ambrosio MR, Di Somma C, Gasperi M, Cannavò S, Scaroni C, Fusco A, Del Monte P, De Menis E, Faustini-Fustini M, Grimaldi F, Logoluso F, Razzore P, Rovere S, Benvenga S, Degli Uberti EC, De Marinis L, Lombardi G, Mantero F, Martino E, Giordano G, Ghigo E: Residual pituitary function after brain injuryinduced hypopituitarism: a prospective I2-month study. J Clin Endocrinol Metab 2005, 90:6085-92. Faculty of 1000 Medicine. 2006 Feb 07.
15. Schneider HJ, Kreitschmann-Andermahr I, Ghigo E, Stalla GK, Agha A: Hypothalamopituitary dysfunction following traumatic brain injury and aneurysmal subarachnoid hemorrhage: a systematic review. JAMA 2007, 298:|429-38.

Changes Clinical Practice

FI000 Factor 9.0 Exceptional

Evaluated by Donald Marion 06 Nov 2007

16. Marion D: Evaluation of: Schneider HJ, Kreitschmann-Andermahr I, Ghigo E, Stalla GK, Agha A: Hypothalamopituitary dysfunction following traumatic brain injury and aneurysmal subarachnoid hemorrhage: a systematic review. JAMA 2007, 298: 1429-38. Faculty of 1000 Medicine. 2007 Nov 06.

17. Klose M, Juul A, Struck J, Morgenthaler NG, Kosteljanetz M, Feldt-Rasmussen U: Acute and long-term pituitary insufficiency in traumatic brain injury: a prospective single-centre study. Clin Endocrinol (Oxf) 2007, 67:598-606.

18. Tanriverdi F, Ulutabanca H, Unluhizarci K, Selcuklu A, Casanueva FF, Kelestimur $F$ : Three years prospective investigation of anterior pituitary function after traumatic brain injury: a pilot study. Clin Endocrinol (Oxf) 2008, 68:573-9.

19. Klose M, Juul A, Poulsgaard L, Kosteljanetz M, Brennum J, Feldt-Rasmussen U: Prevalence and predictive factors of posttraumatic hypopituitarism. Clin Endocrinol (Oxf) 2007, 67: 193-20I.

20. Bavisetty S, McArthur DL, Dusick JR, Wang C, Cohan P, Boscardin WJ, Swerdloff R, Levin H, Chang DJ, Muizelaar JP, Kelly DF: Chronic hypopituitarism after traumatic brain injury: risk assessment and relationship to outcome. Neurosurgery 2008, 62:1080-93.

21. Behan LA, Agha A: Endocrine consequences of adult traumatic brain injury. Horm Res 2007, 68(Suppl 5): I8-2I.

22. Schneider M, Schneider HJ, Yassouridis A, Saller B, von Rosen F, Stalla GK: Predictors of anterior pituitary insufficiency after traumatic brain injury. Clin Endocrinol (Oxf) 2008, 68:206-I2.

23. Agha A, Phillips J, O'Kelly P: The natural history of posttraumatic hypopituitarism: implications for assessment and treatment. Am J Med 2005, I I 8: |4 I6.

24. Schneider HJ, Schneider M, Saller B, Petersenn S, Uhr M, Husemann B, von Rosen F, Stalla GK: Prevalence of anterior pituitary insufficiency 3 and 12 months after traumatic brain injury. Eur J Endocrinol 2006, 154:259-65.

25. Klose M, Watt T, Brennum J, Feldt-Rasmussen U: Posttraumatic hypopituitarism is associated with an unfavorable body composition and lipid profile, and decreased quality of life 12 months after injury. J Clin Endocrinol Metab 2007, 92:386 I-8.

26. Bondanelli M, Ambrosio MR, Cavazzini L, Bertocchi A, Zatelli MC, Carli A, Valle D, Basaglia N, Uberti EC: Anterior pituitary function may predict functional and cognitive outcome in patients with traumatic brain injury undergoing rehabilitation. J Neurotrauma 2007, 24:1687-97.

27. Regal M, Paramo C, Sierra SM, Garcia-Mayor RV: Prevalence and incidence of hypopituitarism in an adult Caucasian population in northwestern Spain. Clin Endocrinol (Oxf) 200I, 55:735-40. 